\title{
A study to evaluate the professional skills of speech therapists in special centers of Karachi
}

\author{
Sumera Azam ${ }^{1}$, Tahmeen Tabish Latifi ${ }^{2}$ \\ ${ }^{1,2}$ Neurology, Liaquat National Hospital, Pakistan
}

\begin{abstract}
The present study was designed "A Study to evaluate the professional skills of speech therapists in special centers of Karachi". The main objectives of the study were to highlight the needs and importance of professional skills of speech therapists; to focus the role of speech therapists in the language development and to investigate the role of parents in speech development of their children. In research nine (9) special schools were selected from different areas of Karachi. Thirty (30) speech therapists were selected as respondents. A structured questionnaire was used to collect data then the data was tabulated and result was maintained through percentage method. Results reveal that there was shortage of speech therapist in special centers. There is lack of equipments for speech therapy according to the requirements of patients. Parents have no awareness about speech therapy therefore parent's involvement was absent. At the end of study it was recommended that management of special centers and hospitals must provide facilities in the special centers and medical hospitals according to the needs of patients with speech problem.
\end{abstract}

Key Words:

Professional Skills: The ability to do something well usually gained through experience and training. In the context of study, the professional skills mean training of speech therapist.

Speech-Language therapist: A speech therapist that treats speech and language defects and disorders. Speech therapy centers: Centers in which problems related to speech-language are treated.

\subsection{Background Of The Study:}

\section{Introduction:}

Clinician is the most universally appropriate term to describe the manner of work of the specialist who provides care for people with speech and language and related problems. It is selected in preference to 'pathologist', who implies a study of disorder or disease without intervention, or 'therapist', which suggests a concentration on treatment. The term clinician may conjure up images of work in medical settings, either at the hospital bedside or in health clinics, and a primary concern for presenting conditions and disorders. However, most importantly, it conveys the message that the specialist concerned is objective and applies a scientific, problem-solving approach to the observation, evaluation and management of people - the clients.

As a speech and language Therapist (SLT) a person may work in hospital or health centre clinics, but there are other places where they can contact clients. Speech Language Therapist might make contact at their place of residence, perhaps the family home or a care home, or in the place they go to in the daytime, such as a day centre or school. Speech Language Therapist may also work in other settings, including resource centers that provide a service for augmentative communication system users.

Human beings Communicate to share ideas, feelings, desires, emotions and for sheet pleasure. We observe and take part in several communicative interactions every day. It serves to maintain relationships amongst all of us. We all are either giving or receiving information throughout the day. We can communicate in many ways. Whatever may be the mode? We do not communicate for no reasons as even an idea talk has a purpose to kill time. People communicate for different reason. These are known as "Functions of communication".

We communicate to satisfy our needs which keep on changing from time of time we not only satisfy our needs. We get information. We interact with people and soon. During a communication act, exchange of information occurs. This exchange of information is not possible without a tool which should be common to both speaker and listener. Man invented language for this purpose. Language is common to a given group of individuals and a given society. Language makes communication easier.

Language is the main vehicle for Communication. Language is a set of arbitrary symbols (Mainly Conventional) use by a group of people for the purpose of communication understanding of language requires the explain action of terms symbol and arbitrary which are given below: 
(1) Symbol

(2) Arbitrary

Symbol is a code that stands for or represents an object, an action or person. Examples of symbols are arranged in an order making use of a set of rules. These rules are shared by the community and are arbitrary. The symbols of language are arbitrary i.e. there is no inherent one to on relationship between the particular spoke written or signed word and the object idea or class of objects it symbolizes. As language is the main vehicle for communication, language essential has same functions as that of communicational. Just like Communication which has different modes. The language has different part. These parts deal with what to say (Content). When to say (use) and how to say word or sentences (form). These parts are called as components of language. We will be able to communicate efficiently by making use of this component.

Speech is the most efficient and frequently used mode of Language expression. Speech is a set of verbal codes; the commonest codes are spoken words. Woods are combined in specific ways to convey meaning. Speech is produced with the help of speech mechanism structures like tongue, jaw, lips etc in a complex coordination with the nervous System. Speech based on the language is useful otherwise it may sound meaningless. Speech and language of a person are accepted as normal, if they resemble to the speech and language of a majority of the people of same age, sex, culture, Socio-economic level and educational level.

The speech and language are abnormal, when these criteria are not met, speech and language of a person can be considered abnormal when they are very different from the speech and language of other people, so they attract attention (unpleasant) and it interfere with communication (difficult to understand) communication problems that people may already have due to birth or people acquired due to accident or other misfortunes. At any stage of child speech and language skills have most importance in his life, speech disorder or language disorders speech therapist plays a important role. Speech therapist should have a deep knowledge about the remedial strategies of different communication problems. By assist and identify the speech / language problem the speech therapist should apply appropriate remedial strategies to remove the speech language problem.

Speech therapist encourages very young children to speak at a slower rote which playing games with them. In Pakistan there are many speech therapist are working in hospitals rehabilitation centers, university speech clinics and hearing centers.

\subsection{Statement Of The Study:}

The present study is designed "A Study about to evaluate the professional skills of speech therapists in special centers of Karachi".

\subsection{Previous Work:}

In my country no previous work was done in this field. This is the first research.

\subsection{Scope Of The Study:}

The recent study will be useful for the special educators in the field of speech therapy. The parents of the special children will also get benefit from this study that they know about the significance of speech therapist in language development. The study helps the teachers for the effective teaching in special schools. The study will be helpful for other researchers.

\subsection{Objectives:}

1. To find out availability of speech therapist in special schools and medical hospitals.

2. To investigate presence of professional speech therapist in institutes.

3. To evaluate incidence of formal testing tools in speech therapy units of institutes.

4. To explore the use of equipment in special centers and medical hospitals for speech therapy.

\subsection{Limitations:}

Due to limited resources in human constrain the study will be confined to Karachi City only.

\subsection{Description Of Population:}

\section{Research Methodology:}

The population of the study was included four medical hospitals and nine special centers from different areas of Karachi city.

\subsection{Sample Of The Study:}

Thirty speech therapists were selected as respondents. 


\subsection{Procedure Of Research:}

Data had been collected from various special centers. The investigator personally visited to these institutions. The Questionnaire was used as an instrument of the study.

\subsection{Instrument Of The Study:}

The questionnaires were developed in the light of objectives and research questions of the study. There were twenty four questions in questionnaire including opened ended and closed ended questions.

\subsection{Data Collection And Analysis:}

Data was collected through interview method. If respondents felt any difficulty, the investigator explained it at the spot. After collection of data it was tabulated and result was maintained through percentage method.

Table \#1 Availability of speech therapist in institutes

\begin{tabular}{|l|l|l|}
\hline Response & Frequency & Percentage \\
\hline Yes & 17 & 57 \\
\hline No & 13 & 43 \\
\hline Total & 30 & 100 \\
\hline
\end{tabular}

Table \# 1 reflect that the higher number 17 (57\%) of the respondents reported that speech therapist is available in various institutes where as $13(43 \%)$ reported their unavailability.

Table\# 2 Presence of professional speech therapist

\begin{tabular}{|l|l|l|}
\hline Response & Frequency & Percentage \\
\hline Degree & 08 & 26 \\
\hline Diploma & 18 & 60 \\
\hline Untrained & 4 & 14 \\
\hline Total & 30 & 100 \\
\hline
\end{tabular}

Table \#2 discuss the professional qualification of the available speech therapist at the institues. Most of the speech therapist $(60 \%)$ have one year diploma in the field where as $26 \%$ speech therapist had proper degree in the subjects. Further more 14\% are not professionally qualified.

Table \# 3 Formal testing tools

\begin{tabular}{|l|l|l|}
\hline Response & Frequency & Percentage \\
\hline Yes & 2 & 5 \\
\hline No & 18 & 60 \\
\hline To some extent & 10 & 35 \\
\hline Total & 30 & 100 \\
\hline
\end{tabular}

Table \# 3 shows that a large number of population $(60 \%)$ have not standardized tools for assessment and treatment purpose. On the other hand only $5 \%$ respondents have formal testing and treatment tools.

Table\# 4 Use of equipment

\begin{tabular}{|l|l|l|}
\hline Response & Frequency & Percentage \\
\hline Yes & 7 & 24 \\
\hline No & 11 & 36 \\
\hline To some extent & 12 & 40 \\
\hline Total & 30 & 100 \\
\hline
\end{tabular}

Table \#4 demonstrates that $40 \%$ respondents use a combination of modern and traditional tools during therapy. While $36 \%$ respondent use traditional therapy tools.

\section{Conclusion:}

From the results of this study it is concluded that according to the needs of special centers and hospitals there is a lack of required numbers of speech therapist working at this places. According to a survey report published in daily Dawn it is estimated over 22 million individuals in an overall population of over 160 million suffered from speech, language, swallowing and hearing disorder and our country have very small number of qualified SLP to cater the needs of 22 million individuals across the nation. Further more most of the speech therapists at the above institutes don't have professional degree in the field therefore they lacked the professional assessment procedures, design appropriate treatment plans, conduct therapeutic measures, draw 
inference from treatment objectives and prepare home modification strategies for children with speech language problems. It was also discussed during the study that due to financial constrain, limited professional expertise, and time limitations the formal testing tools for assessment and treatment were not acquired by the institutes of the study which may shows that standardized procedure to trigger peculiar areas of treatment couldn't figure out. This study also revealed that most of the speech therapist use traditional mean of treatment for cater the needs of there patients. More over a combination of modern and traditional therapy materials were used for the management purpose a paradigm shift is needed to explore the world of speech and language pathology.

\section{Acknowledgements}

With all humble gratitude and humility at my command, I sincerely thanks Dr. Nasir Salman my supervisor. I also thankful to Ms Shahana Shams librarian Special Education department at University of Karachi. Thanks is also due to Mr. Abid Rafi for his time and continuous involvement during the whole course. I would also like to thank the school and hospital staff who participate in my study. Last but not the least I extremely thankful to the parents ,professionals and children with special needs to participate in the study.

\section{Books:}

\section{References:}

[1] Silverman, David(2005). Doing Qualitative Research $\left(2^{\text {nd }}\right.$ Ed). London: Sage Publications.

[2] Schubert, G. (2000) Introduction to Clinical Supervision in Speech Pathology.

\section{Journals papers}

[3] National Institute for the Mentally Handicapped (2004) Diploma Special Education Mental Retardation Secundarabad, Ministry of Welfare, Government of India.

\section{Theses}

[4] Naheed Bano (2006) Techniques of Speech Therapy Karachi, Department of Special Education, University of Karachi. 